\title{
Psychological and Neural Correlates of Embitterment in Old Age
}

\author{
Simone Kühn \\ Max Planck Institute for Human Development, Berlin, Germany, \\ and University Clinic Hamburg-Eppendorf \\ Sandra Düzel \\ Max Planck Institute for Human Development, Berlin, Germany \\ Johanna Drewelies and Denis Gerstorf
Humboldt-Universität zu Berlin \\ Ulman Lindenberger \\ Max Planck Institute for Human Development, Berlin, Germany, \\ and UCL Centre for Computational Psychiatry and Ageing \\ Research, Berlin, Germany
}

\author{
Jürgen Gallinat \\ University Clinic Hamburg-Eppendorf
}

\begin{abstract}
Objective: Posttraumatic embitterment disorder (PTED) comprises a stress-related response to a negative life event that violates the belief system of the individual. Characteristic symptoms involve repeated intrusive thoughts, emotional arousal when reminded of the event, and decreases in well-being. Method: Within the scope of the present study, embitterment was treated as a continuous rather than categorical concept, and we investigated its psychological and brain structural correlates in a sample of healthy older adults. Results: We found a negative association between the PTED self-rating score and self-reported well-being, life satisfaction, and future time perspective and a positive association with loneliness, perceived stress, chronic strain, and external control beliefs. We found no significant association between embitterment and brain regions that have been associated with stress exposure and posttraumatic stress disorder (PTSD) - hippocampus and the medial prefrontal cortex. This may emphasize the fundamental difference between PTED and PTSD. In a whole-brain analysis, we found a positive correlation between embitterment and gray matter volume in the precuneus and white matter volume in the bilateral uncinate fasciculus. Conclusions: The precuneus and uncinate fasciculus are brain regions that have been related to episodic memory retrieval, matching well to the symptoms of intrusive thoughts and an overwhelming preoccupation with the event that caused the PTED. Further longitudinal research is needed to unravel whether these structural correlates represent preconditions or rather the consequence of embitterment.
\end{abstract}

Keywords: embitterment, voxel-based morphometry, magnetic resonance imaging, posttraumatic embitterment disorder, posttraumatic stress disorder

Posttraumatic embitterment disorder (PTED) has been described as a response to an exceptional critical life event that has insulted, upset, or humiliated the individual (Linden, Rotter, Baumann, \& Lieberei 2006). Other than in the definition of posttraumatic stress disorder (PTSD), this life event may not be anxiety-provoking or life-threatening, but it can be a more or less common negative life event such as unemployment, divorce, or illness that still leads to considerable stress responses in certain individuals. As a potential pathogenic mechanism of PTED, a violation of the patients' basic beliefs has been discussed (Linden, Baumann, Rotter, \& Schippan, 2008a). This threat of the basic beliefs acts as a trigger for prolonged feelings of bitterness, helplessness, and rage. Characteristic symptoms resulting from this event resemble other stressrelated syndromes and involve repeated intrusive thoughts, emo-
Simone Kühn, Center for Lifespan Psychology, Max Planck Institute for Human Development, Berlin, Germany, and Clinic and Policlinic for Psychiatry and Psychotherapy, University Clinic Hamburg-Eppendorf; Sandra Düzel, Center for Lifespan Psychology, Max Planck Institute for Human Development; Johanna Drewelies and Denis Gerstorf, Institute of Psychology, Humboldt-Universität zu Berlin; Ulman Lindenberger, Center for Lifespan Psychology, Max Planck Institute for Human Development, and Max Planck UCL Centre for Computational Psychiatry and Ageing Research, Berlin, Germany; Jürgen Gallinat, Clinic and Policlinic for Psychiatry and Psychotherapy, University Clinic Hamburg-Eppendorf.

The authors are grateful for the assistance of the MRI team at the Max Plank Institute Berlin, consisting of Sonali Beckmann, Nils
Bodammer, Thomas Feg, Sebastian Schröder, and Nadine Taube. This article uses data from BASE-II, which has been supported by the German Federal Ministry of Education and Research under grant 16SV5537/16SV5837/16SV5538/16SV5536K/01UW0808/01UW0706. The responsibility for the contents of this publication lies with its authors. Simone Kühn has been supported by a grant from the European Union (ERC-2016-StG-Self-Control-677804) and the DFG KU 3322/ $1-1$.

Correspondence concerning this article should be addressed to Simone Kühn, Clinic and Policlinic for Psychiatry and Psychotherapy, University Clinic Hamburg-Eppendorf, Martinistraße 52, 20246 Hamburg, Germany. E-mail: skuehn@uke.de 
tional arousal when reminded of the event, changes in well-being, and an impairment in the performance of daily activities. A crucial feature of PTED is that individuals themselves see and describe the event as the cause of their illness. One of the diagnostic criteria is that the symptoms persist for more than 6 months. The prevalence rate has been estimated as $2-3 \%$ in the general population (Linden et al., 2006).

Previous PTED studies have mostly focused on patients fulfilling the diagnostic criteria of PTED and have compared them with healthy controls or other patient groups. These studies have demonstrated that PTED patients score high on scales assessing psychopathological complaints and that they suffer from feelings of injustice, embitterment, and rage and show a high prevalence of stress (Linden, Baumann, Rotter, \& Schippan, 2007, 2008b). The fact that PTED is accompanied by a stress response suggests a connection to a whole cascade of bodily responses and somatic consequences. The detrimental effects of stress on physical and mental health have long been recognized. On an endocrinological level, the stress response is characterized by activation of the sympathetic system and hypothalamus pituitary adrenal (HPA) axis and release of epinephrine, norepinephrine, and glucocorticoids (Lupien, McEwen, Gunnar, \& Heim, 2009). Although the stress response is known to be adaptive in the short term, chronic stress may have serious somatic consequences (Deppermann, Storchak, Fallgatter, \& Ehlis, 2014; McEwen, 2013). It is interesting to note that a study comparing various laboratory measures of global health capturing markers of the endocrine, neuroimmunological, and metabolic system between PTED patients and patients with a psychosomatic disorder did not find any differences between the two clinical groups (Bruenahl \& Linden, 2011). However, there is strong evidence that chronic stress leads to a continuous release of glucocorticoids, which has in turn been associated with reductions in neurogenesis and dendritic atrophy in the brain. Specifically, the hippocampus (Sapolsky, Krey, \& McEwen, 1985) and prefrontal cortex (McEwen \& Morrison, 2013) have been related to chronic stress exposure in general and PTSD in particular (Kühn \& Gallinat, 2013). On the basis of these previous findings, we set out to investigate whether the neurobiological concept of stress and trauma as developed within the PTSD literature applies to PTED or whether stress and trauma are more multifaceted than commonly thought.

Within the scope of the present study, we aimed at investigating associations between embitterment and other psychological variables that have been linked to mental health and to brain structure. To assess the construct embitterment in a dimensional manner, we recruited participants of the Berlin Aging Study 2 (BASE-II; Bertram et al., 2014; Gerstorf et al., 2016) with magnetic resonance imaging (MRI) data and PTED self-rating scale data (Linden, Baumann, Lieberei, \& Rotter, 2009). We hypothesized relationships between embitterment and our psychological variables as well as hippocampal and prefrontal gray matter volume.

\section{Method}

\section{Participants and Study Design}

Participants from the BASE-II (for cohort characteristics and more, see Bertram et al., 2014; Gerstorf et al., 2016) were recruited to take part in an imaging study. After completion of a compre- hensive cognitive and psychological examination, eligible participants were invited to take part in one MRI session within a time window of 2-4 weeks after testing. The first neuroimaging wave consisted of 102 young adults (aged 24-38 years, mean age 30.8, $S D=3.57 ; 38$ female) and 341 older adults (aged 61-82 years, mean age $70.1, S D=3.89 ; 131$ female). The present study is based on cognitive, psychological, and neuroimaging follow-up data assessed approximately 2 years after the first data acquisition consisting of 71 young adults (aged 25-40 years, mean age 32.7, $S D=3.66 ; 22$ female) and 253 older adults (aged 62-83 years, mean age 72.4, $S D=4.06$; 91 female). We will focus on 230 older adults from whom we obtained data on embitterment next to neuroimaging data.

None of the participants took any medication that may have affected memory function or had a history of head injuries, medical (e.g., heart attack), neurological (e.g., epilepsy), or psychiatric disorders (e.g., depression). All participants had completed at least 8 years of education. The different subparts of the study were approved by the ethics committees of the Max Planck Institute for Human Development, Charité University, and the German Society of Psychology. Participants signed written informed consent and received monetary compensation for their participation in BASE-II and the MRI study.

\section{MRI Acquisition}

All images were acquired on a Siemens Tim Trio 3T scanner (Erlangen, Germany) using a 32-channel head coil. The T1 images were obtained using a three-dimensional T1-weighted magnetization prepared gradient-echo sequence (MPRAGE) based on the ADNI protocol (www.adni-info.org; repetition time [TR] $=2,500$ msec; echo time $[\mathrm{TE}]=4.77 \mathrm{msec}$; $\mathrm{TI}=1,100 \mathrm{msec}$, acquisition matrix $=256 \times 256 \times 176$, flip angle $=7^{\circ} ; 1 \times 1 \times 1 \mathrm{~mm}$ voxel size).

\section{Questionnaires}

Embitterment. Embitterment was assessed using the PTED Self-Rating Scale (Linden et al., 2009), which is composed of 19 items aiming to assess features of embitterment reactions in the aftermath of negative life events. Each question was prompted with the words "During the last years there was a severe and negative life event ..." and was then followed by 19 individual statements such as "... that causes me to be extremely upset when I am reminded of it." Participants were asked to indicate for each item on a 5-point scale to what degree the statement applies to them $(0=$ not at all true to $4=$ extremely true $)$. Cronbach's $\alpha$ value in the present study was .93 , indicating high internal consistency, same as in the initial study by Linden and colleagues (2009).

Subjective well-being. Subjective well-being was assessed by the five-item scale proposed by Diener, Emmons, Larsen, and Griffin (1985). Although the original scale offers a 7-point rating scale, we decided to use a 5-point scale, ranging from 1 (strong disagreement) to 5 (strong agreement), to make the response format more similar across the different instruments. Cronbach's $\alpha$ value in the present study was .85 .

Life satisfaction. Life satisfaction was measured based on the Philadelphia Geriatric Center Morale Scale (PGCMS; Lawton, 
1975; Liang \& Bollen, 1983), which is widely used as a measure of morale, psychological well-being, life satisfaction, and quality of life in elderly populations. We used three items, including "I sometimes feel that life is not worth living" (item 9), "I have a lot to be sad about" (item 11), and "I take things hard" (item 16), constituting the life satisfaction subscale. Participants responded on a 5-point scale ranging from 1 (strongly disagree) to 5 (strongly agree). Although these items do not load on the same scale within the complete PGCMS, we have built a composite score with an acceptable Cronbach's alpha of .78.

Loneliness. Loneliness was measured by means of the University of California-Los Angeles (UCLA) Loneliness Scale (Russell, Cutrona, Rose, \& Yurko, 1984), consisting of seven items. Participants were asked to rate each statement on a 5-point scale ranging from 1 (strongly disagree) to 5 (strongly agree). Higher scores indicate stronger feelings of loneliness. Cronbach's $\alpha$ value in the present study was .82. To assess the objective number of close confidants, we used a single item in which we asked participants to indicate how many close friends they have.

Future time horizon. We used the 10 -item scale to assess the future time horizon (Carstensen \& Lang, 1996). Participants indicated the degree to which they agreed with an item on a scale ranging from 1 (very untrue) to 7 (very true for me). We used a scale composite consisting of the unit-weighted mean over all items, and lower scores indicate a limited future time horizon. Cronbach's $\alpha$ value in the present study was .91 .

Control beliefs. Three dimensions of generalized perceived control were assessed by means of a self-report measure consisting of a 14-item questionnaire (Gerstorf, Ram, Lindenberger, \& Smith, 2013; Kunzmann, Little, \& Smith, 2002). Six items assessed beliefs in personal control over undesirable and desirable outcomes (e.g., "I can make sure that good things come my way."), and eight items assessed beliefs in external control such as fate or luck over undesirable and desirable outcomes or powerful others (e.g., "The good things in my life are, for the most part, a matter of luck."). Participants were asked to indicate the extent to which they agreed with each of the items using a 5-point scale from 1 (does not apply to me at all) to 5 (applies very well to me). Cronbach's $\alpha$ value for internal control was .69, for external control-fate/chance was .44, and for external control-powerful others was .70 .

Chronic strain. Was assessed using the Trier Inventory for the Assessment of Chronic Stress (TICS; Schulz, Scholtz, \& Becker, 2004). Using a 5-point scale ranging from 0 (never) to 4 (very often), participants responded to six items constituting the chronic strain subscale (we omitted the two last items based on scale properties such as discriminatory power and reliability in a pilot study). All items were to be answered under the header "During the last 12 months how often have you experienced this situation?" Cronbach's $\alpha$ value in the present study was .88 .

Perceived stress. Perceived stress was assessed using the Perceived Stress Scale by Cohen, Kamarck, and Mermelstein (1983). Participants responded on a 5-point scale ranging from 0 (never) to 4 (very often). All statements start with the phrasing "In the last month, ..." and assess perceptions of stress. The 10 items were reduced to 8 items (we omitted items 6 and 9 based on scale properties such as discriminatory power and reliability in a pilot study). Cronbach's $\alpha$ value in the present study was .81 .

\section{Questionnaire Data Analysis}

Because the embitterment scale was not normally distributed, we used nonparametric partial correlation coefficients (Sprent, 1998) to control for age and sex while investigating the association between the questionnaire data and embitterment. We chose a threshold of $p<.001$ to correct for multiple testing. According to Bonferroni, ten independent tests would require a threshold of $p<$ .005 , when the threshold for each individual correlation is set to $p<.05$.

\section{Voxel-Based Morphometry Preprocessing}

Structural data were processed by means of VBM8 (http://dbm .neuro.uni-jena.de/vbm.html) and SPM8 (http://www.fil.ion.ucl.ac .uk/spm) using default parameters. VBM8 involves bias correction, tissue classification, and affine registration. The affine-registered gray matter (GM) and white matter (WM) segmentations were used to build a customized DARTEL (diffeomorphic anatomical registration through exponentiated lie algebra) template. Warped GM and WM segments were then created. Modulation with Jacobian determinants was applied to preserve the volume of a particular tissue within a voxel, leading to a measure of volume of GM. Images were smoothed with a full-width at half maximum (FWHM) kernel of $8 \mathrm{~mm}$. Statistical analysis was performed by means of whole-brain correlation of GM/WM volume and self-reported embitterment. Age, sex, and whole-brain volume were entered as covariates of no interest. The resulting maps were thresholded with $p<.001$, and the statistical extent threshold was used to correct for multiple comparisons combined with a nonstationary smoothness correction based on permutation as proposed by Hayasaka and Nichols (2004).

\section{Region of Interest Extraction}

On the basis of prior studies on the consequences of stress on the brain, we focused on the bilateral hippocampus and medial prefrontal cortex (combining bilateral frontal orbital cortex and gyrus rectus) as defined by the automated anatomical labeling atlas (Tzourio-Mazoyer et al., 2002).

\section{Results}

On average, the sample had a mean embitterment score of 0.56 (range $0-3.47, S D=0.66$ ). When embitterment is defined as a score of $>2,4.3 \%$ of the sample would classify as clinically embittered. With a definition of $>1.6$, as has been suggested by a discriminant function that was run on data of patients suffering from PTED and controls, indicating an intensity of clinical relevance (Linden et al., 2006), the diagnosis would apply to $7.1 \%$ of the sample. The rates of PTED in the present study are slightly higher compared with the nonclinical sample presented in Linden et al. (2009), in which $2.5 \%$ of the sample had a score $>2$, most likely because the latter sample was clearly younger with an age range of 20-65 years.

Because the present study comprises a healthy older convenience sample, we decided against treating embitterment as a discrete diagnosis but used the PTED score as a continuous indicator of embitterment. To test for the association between various psychological concepts and embitterment, we used nonparametric partial correlation controlling for sex and age. We found a signif- 
icant negative association between embitterment and well-being, life satisfaction, and future time perspective (Figure 1). A positive association was found between embitterment and loneliness, stress measured by means of the perceived stress scale and the chronic strain subscale of the TICS, and external control beliefs for both fate/change and powerful others.

We then conducted a hypothesis-driven region of interest (ROI) analysis on GM volumes extracted from the bilateral hippocampus and bilateral medial prefrontal cortex. While controlling for sex and age, we did not find a significant association between embitterment and bilateral hippocampus $(r(225)=-0.021, p=.755)$ and medial prefrontal cortex $(r(225)=0.059, p=.380)$.

Furthermore, we ran a hypothesis-free whole-brain analysis on GM and WM maps in search of neural correlates of embitterment. In the GM maps, we found a significant positive correlation for embitterment in the precuneus, more precisely in the retrosplenial cortex ( $-9-4515$, MNI coordinates, Figure 2A). In WM, we found a positive correlation of embitterment with bilateral clusters in the uncinate fasciculus ( $-1422-15,2122-12$, Figure $2 B)$, the tract connecting the limbic system such as the hippocampus and amygdala with frontal regions, including the orbitofrontal cortex.

\section{Discussion}

Within the scope of the present study, we aimed at investigating psychological and brain structural correlates of embitterment in a sample of healthy older adults. Because the sample was not clinical, we used embitterment as a continuous variable, not as a discrete clinical diagnosis. In line with our expectations, we found a negative association between the PTED self-rating score and self-reported well-being, life satisfaction, and future time perspective and a positive association with loneliness, perceived stress, chronic strain, and external control beliefs as well as a scale assessing how much control is ascribed to others. Contrary to our a priori hypothesis based on our knowledge of prominent neural

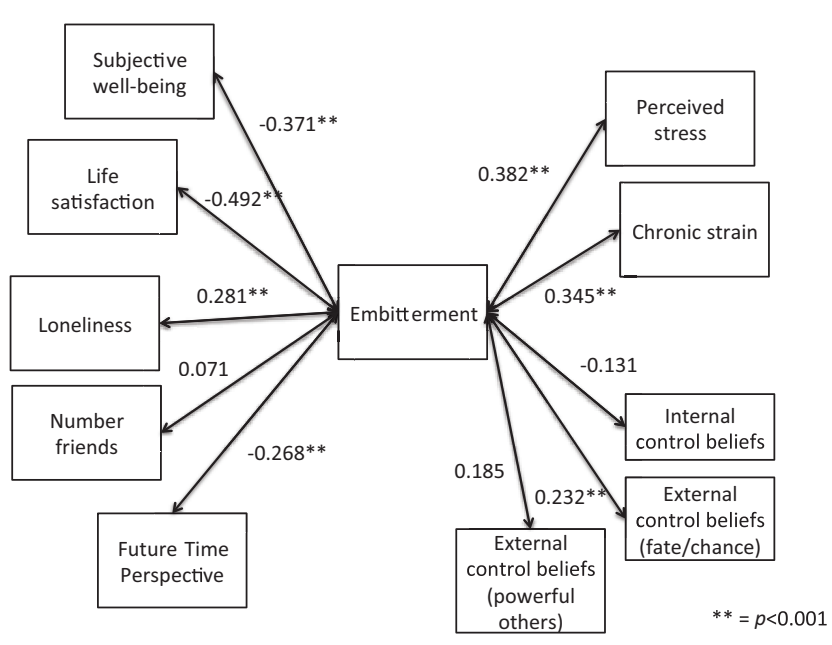

Figure 1. Associations between embitterment and other scales assessing psychological well-being, stress, and control beliefs. The results reflect associations derived from nonparametric partial correlations controlling for sex and age. ${ }^{* *} p<.001$.



Figure 2. Positive correlates of embitterment in (A) GM and (B) WM controlling for sex, age, and whole-brain volume $(p<.001$, cluster and nonstationary smoothness corrected). See the online article for the color version of this figure.

correlates of PTSD, we found no significant association between embitterment and brain volume in the hippocampus and the medial prefrontal cortex. Instead, we found a positive correlation between embitterment and GM volume in the precuneus and WM volume in bilateral uncinate fasciculus.

\section{Embitterment and Psychological Self-Report Scales}

The observed negative correlation between embitterment and subjective well-being reflects the diagnostic symptoms of PTED, which by definition involve a persistent negative change in mental well-being (Linden et al., 2008a). Likewise, the associated reduction in life satisfaction and the positive correlation with measures of stress and strain can be derived from the clinical definition of PTED. The later association reflects the classification of PTED as a stress-related psychiatric disorder.

However, the negative relationship between embitterment and future time perspective, loneliness, and control beliefs may be a little further away from the actual diagnostic criteria of PTED and potentially a consequence of PTED. Future time perspective assesses how individuals look at their future (Carstensen \& Lang, 1996). In midlife, many adults start focusing on the time left to live rather than the time they have already lived. Future time perspective is defined as the perceptions and expectations an individual has with regard to his or her future. The scale assesses to what extent the future is perceived as open-ended, harboring many opportunities still to come, or as being limited and closed (Carstensen, Isaacowitz, \& Charles, 1999). Our results suggest that embitterment goes along with a shortening of time perspective perceived by the individual.

Likewise, embitterment was positively associated with loneliness, which may be seen as being in line with the description of PTED patients as impaired in the performance of daily activities and roles. However, the direct consequence of an impairment in daily activities would be a reduction of actual social contact (for example, as self-reported number of friends). It is interesting to note that this variable was not associated with embitterment; in contrast, the perception of the objective social integration (namely, the feeling of loneliness) was increased in embitterment. This pattern of correlations also fits to the notion that PTED patients 
report the feeling that nobody stands by them and social partners are perceived as enemies.

The fact that external control beliefs ascribed to powerful others and fate/chance was positively associated with embitterment fits well with the definition of PTED that comprises the feeling of helplessness. In the context of helplessness research, the importance of causal ascriptions has been discussed. The perceived causes or the attribution of learned helplessness can be specified on three dimensions: stability/instability, globality/specificity, and internality/externality (Abramson, Seligman, \& Teasdale, 1978). The stability attribution would indicate that causes are general and will not change, the globality attribution comprises the belief that the causes are consistent across different contexts, and the externality attribution ascribes causality to external factors. The individuals' attribution has an impact on the expectations of future helplessness. The fact that we see a positive relationship between external control beliefs, as well as the beliefs that others are in control, and embitterment may be a mechanism that manifests the feeling of helplessness in PTED.

\section{Embitterment and Brain Structure}

PTSD has been frequently associated with volumetric reductions in the hippocampus and medial prefrontal cortex (Kühn \& Gallinat, 2013). Likewise, animal studies have demonstrated that dendritic modifications of hippocampal neurons can be caused by various chronic stress conditions and can be reversed after stressfree recovery periods (Magariños \& McEwen, 1995). This dendritic remodeling in response to stress seems to extend across several species, including mice and rats (McKittrick et al., 2000; Vyas, Mitra, Shankaranarayana Rao, \& Chattarji, 2002). A human postmortem study has presented evidence for similar structural changes in individuals who had experienced high levels of psychological distress (Soetanto et al., 2010). However, contrary to the fact that PTED is a stress-related mental disorder and contrary to the observation that embitterment is associated with scales assessing self-reported perceived stress and strain, we found no association with brain regions that have been previously related to stress exposure-neither to hippocampal volume nor medial prefrontal cortex and embitterment.

To explore potential associations between brain structure and embitterment in a less theory-driven manner than the previous ROI analysis, we conducted a whole-brain analysis in which embitterment was correlated with GM and WM volume in a voxel-wise fashion. Here, we observed more GM volume with higher embitterment scores in the precuneus and more WM volume in the bilateral uncinate fasciculus. We found no regions showing a significant negative correlation with embitterment.

The precuneus has traditionally received little attention in functional and structural neuroimaging research. This may be due to the fact that the precuneus is not often involved in focal lesions. It is interesting to note that functional magnetic resonance imaging (fMRI) studies have demonstrated that the precuneus plays a role in episodic memory retrieval, self-reflective processing, and visuospatial imagery (Cavanna \& Trimble, 2006). In the context of embitterment, the role of the precuneus in episodic memory and self-reflective processing is most interesting. Episodic memory comprises the storage and recall of previously experienced events, and it has been defined to cover autobiographical memory (Tulv- ing, 1983). In turn, autobiographical memory is strongly related to self-processing because it grounds the self, and self-related processes in turn influence the content and organization of autobiographical memory. In line with this, autobiographical memory has also been related to the precuneus (Fossati, 2013). The role of the precuneus in self-reflective processing has frequently been investigated using fMRI paradigms in which judgment on self-relevant traits compared to self-irrelevant traits were compared (Kircher et al., 2000) or in which responding to semantic statements was compared to responding to self-relevant statements (Zysset, Huber, Ferstl, \& von Cramon, 2002). One may be tempted to speculate that the prolonged rumination about the negative life event that caused the embitterment and that threatened the belief system of the individual caused a structural increase in the precuneus over time. However, to our knowledge there are at present only two studies that investigated structural GM changes over the course of an episodic memory training in healthy controls and patients with subjective memory complaints, and although they do report cortical thickness increases in regions associated with episodic memory (prefrontal, temporal, supramarginal cortex, insula), they did not observe increases in the precuneus (Engvig et al., 2010, 2014). Because we only acquired cross-sectional data, no causal directionality can be derived. That is, it could well be that individuals with more GM in the precuneus are more likely to suffer from embitterment when faced with a negative life event because the precuneus works more effectively.

A function that the precuneus has also been associated with is guilt; among several other brain regions, the precuneus has been highlighted in two quantitative meta-analyses (Bastin, Harrison, Davey, Moll, \& Whittle, 2016; Gifuni, Kendal, \& Jollant, 2016). The fMRI paradigms of the data included in these meta-analyses all conceptualized guilt as directed to oneself, not to others. Although self-blame is also listed as one of the symptoms in PTED, the more prominent emotion is the attribution of guilt to others, not to oneself. However, to our knowledge studies on the involvement of the precuneus in blaming others do not exist thus far. Therefore, we think that the higher GM volume in the precuneus associated with embitterment should rather be interpreted in the light of episodic memory function.

The uncinate fasciculus, which was positively correlated with embitterment scores in both hemispheres, is a WM tract that connects the orbitofrontal cortex with the anterior temporal lobe and is therewith associated with the limbic system of the brain. Anatomically, the uncinate fasciculus has been divided into three parts: a dorsal-temporal segment, a middle-insular segment, and a ventral-frontal segment (Ebeling \& von Cramon, 1992). The cluster associated with embitterment was located in the latter ventralfrontal segment. Its function is assumed to comprise episodic memory and emotion processing because it connects the temporal lobe with brain regions responsible for the evaluation of stimuli (Von Der Heide, Skipper, Klobusicky, \& Olson, 2013). It is interesting to note that studies on monkeys in which the uncinate fasciculus has been disconnected do not show impairments in various memory-associated tasks such as reversal learning, objectreward association learning, and delayed matching to sample (Eacott \& Gaffan, 1992; Gaffan \& Eacott, 1995; Gutnikov, Ma, Buckley, \& Gaffan, 1997); however, conditional rule learning seems to be consistently impaired when a cue at the beginning informs the animal of what choices will be rewarded (Bussey et al., 
2002; Gutnikov et al., 1997). One potential interpretation of this finding is that the uncinate fasciculus is involved in mnemonic associations accomplished by the temporal lobe and modulated by valence-based decision-making achieved by the orbitofrontal cortex (Von Der Heide et al., 2013). The positive correlation between the bilateral uncinate fasciculus and embitterment fits well to the GM cluster observed in the precuneus, which may also reflect an association of embitterment with episodic memory functioning. The type of memory might also explain why the structural basis of PTSD and PTED is different (Linden \& Rutkowski, 2013). A common feature of PTSD and PTED is that in both conditions vivid images come to mind involuntarily and with high frequency. However, the core mechanism in PTSD is the urge to flee these situations and/or images (i.e., avoidance behavior) whereas in PTED the thoughts are more nagging because something is unsolved. This could be based on a Zeigarnik effect (Zeigarnik, 1927), reflecting the phenomenon that unfinished tasks keep psychological processing alive and patients cannot be done with what happened. Memories are intrusive and hurting but at the same time welcome because thinking about what has happened can even have for short moments a consoling effect. Therefore, the structural basis of PTED may be more overlapping with brain regions known to be involved in episodic memory retrieval. However, as mentioned previously, the cross-sectional nature of the present findings do not allow us to infer whether this alteration in brain structure is a precondition for embitterment or whether the structural correlates reflect consequences of embitterment and its associated symptoms such as rumination and an extensive preoccupation with the negative life event that violated the individuals' beliefs and caused the embitterment.

The observed absence of an association between PTED and brain regions known to be affected by PTSD and the finding of neural correlates in the precuneus and uncinate fasciculus is highly interesting because it shows that stress associated with PTSD, which has mostly been associated with anxiety and physiological arousal, may be fundamentally different from stress associated with PTED, which has been linked to memories of humiliation and experience of injustice on the neurobiological level. Taken together, the present findings reveal highly plausible psychological correlates of embitterment in a sample of healthy older adults. This encourages the use of the PTED questionnaire as a dimensional measure of embitterment. The absence of an association of embitterment with well-recognized brain regions associated with stress and PTSD, namely hippocampus and medial prefrontal cortex, is interesting and may be seen as evidence arguing in favor of a separation between PTED and PTSD. The results of an exploratory whole brain analysis, namely a positive association between embitterment and GM volume in the precuneus and WM volume in the uncinate fasciculus, suggest a link between embitterment and enhanced self-referential episodic memory processing. Whether this is rather a precondition that fosters the development of embitterment in the face of negative life events that violate individuals belief systems or whether it is a consequence of the intrusive thoughts and repetitive preoccupation with the events is unclear and should be addressed by future longitudinal research. It is important to note that we think that the present results suggest that stress is not a uniform phenomenon and that potentially different forms of stress should be thoroughly discriminated.

\section{References}

Abramson, L. Y., Seligman, M. E., \& Teasdale, J. D. (1978). Learned helplessness in humans: Critique and reformulation. Journal of Abnormal Psychology, 87, 49-74. http://dx.doi.org/10.1037/0021-843X.87 .1 .49

Bastin, C., Harrison, B. J., Davey, C. G., Moll, J., \& Whittle, S. (2016). Feelings of shame, embarrassment and guilt and their neural correlates: A systematic review. Neuroscience and Biobehavioral Reviews, 71, 455-471. http://dx.doi.org/10.1016/j.neubiorev.2016.09.019

Bertram, L., Böckenhoff, A., Demuth, I., Düzel, S., Eckardt, R., Li, S. C., . . . Steinhagen-Thiessen, E. (2014). Cohort profile: The Berlin Aging Study II (BASE-II). International Journal of Epidemiology, 43, 703712. http://dx.doi.org/10.1093/ije/dyt018

Bruenahl, C. A., \& Linden, M. (2011). Common laboratory measures of global health may not be suited to assess, discriminate or predict chronic stress effects on biological systems. Nordic Journal of Psychiatry, 65, 266-268. http://dx.doi.org/10.3109/08039488.2010.542589

Bussey, T. J., Wise, S. P., \& Murray, E. A. (2002). Interaction of ventral and orbital prefrontal cortex with inferotemporal cortex in conditional visuomotor learning. Behavioral Neuroscience, 116, 703-715. http://dx .doi.org/10.1037/0735-7044.116.4.703

Carstensen, L. L., Isaacowitz, D. M., \& Charles, S. T. (1999). Taking time seriously. A theory of socioemotional selectivity. American Psychologist, 54, 165-181. http://dx.doi.org/10.1037/0003-066X.54.3.165

Carstensen, L., \& Lang, F. R. (1996). Future Time Perspective Scale. Stanford, CA: Stanford University.

Cavanna, A. E., \& Trimble, M. R. (2006). The precuneus: A review of its functional anatomy and behavioural correlates. Brain: A Journal of Neurology, 129, 564-583. http://dx.doi.org/10.1093/brain/aw1004

Cohen, S., Kamarck, T., \& Mermelstein, R. (1983). A global measure of perceived stress. Journal of Health and Social Behavior, 24, 385-396. http://dx.doi.org/10.2307/2136404

Deppermann, S., Storchak, H., Fallgatter, A. J., \& Ehlis, A. C. (2014). Stress-induced neuroplasticity: (Mal)adaptation to adverse life events in patients with PTSD_A critical overview. Neuroscience, 283, 166-177. http://dx.doi.org/10.1016/j.neuroscience.2014.08.037

Diener, E., Emmons, R. A., Larsen, R. J., \& Griffin, S. (1985). The Satisfaction With Life Scale. Journal of Personality Assessment, 49, 71-75. http://dx.doi.org/10.1207/s15327752jpa4901_13

Eacott, M. J., \& Gaffan, D. (1992). Inferotemporal-frontal disconnection: The uncinate fascicle and visual associative learning in monkeys. $E u$ ropean Journal of Neuroscience, 4, 1320-1332. http://dx.doi.org/10 .1111/j.1460-9568.1992.tb00157.x

Ebeling, U., \& von Cramon, D. (1992). Topography of the uncinate fascicle and adjacent temporal fiber tracts. Acta Neurochirurgica, 115, 143-148. http://dx.doi.org/10.1007/BF01406373

Engvig, A., Fjell, A. M., Westlye, L. T., Moberget, T., Sundseth, Ø., Larsen, V. A., \& Walhovd, K. B. (2010). Effects of memory training on cortical thickness in the elderly. NeuroImage, 52, 1667-1676. http://dx .doi.org/10.1016/j.neuroimage.2010.05.041

Engvig, A., Fjell, A. M., Westlye, L. T., Skaane, N. V., Dale, A. M., Holland, D., . . . Walhovd, K. B. (2014). Effects of cognitive training on gray matter volumes in memory clinic patients with subjective memory impairment. Journal of Alzheimer's Disease, 41, 779-791.

Fossati, P. (2013). Imaging autobiographical memory. Dialogues in Clinical Neuroscience, 15, 487-490.

Gaffan, D., \& Eacott, M. J. (1995). Visual learning for an auditory secondary reinforcer by macaques is intact after uncinate fascicle section: Indirect evidence for the involvement of the corpus striatum. European Journal of Neuroscience, 7, 1866-1871. http://dx.doi.org/10 .1111/j.1460-9568.1995.tb00707.x

Gerstorf, D., Bertram, L., Lindenberger, U., Pawelec, G., Demuth, I., Steinhagen-Thiessen, E., \& Wagner, G. G. (2016). Editorial. Gerontology, 62, 311-315. http://dx.doi.org/10.1159/000441495 
Gerstorf, D., Ram, N., Lindenberger, U., \& Smith, J. (2013). Age and time-to-death trajectories of change in indicators of cognitive, sensory, physical, health, social, and self-related functions. Developmental Psychology, 49, 1805-1821. http://dx.doi.org/10.1037/a0031340

Gifuni, A. J., Kendal, A., \& Jollant, F. (2016). Neural mapping of guilt: A quantitative meta-analysis of functional imaging studies. Brain Imaging and Behavior. Advance online publication. http://dx.doi.org/10.1007/ s11682-016-9606-6

Gutnikov, S. A., Ma, Y. Y., Buckley, M. J., \& Gaffan, D. (1997). Monkeys can associate visual stimuli with reward delayed by $1 \mathrm{~s}$ even after perirhinal cortex ablation, uncinate fascicle section or amygdalectomy. Behavioural Brain Research, 87, 85-96. http://dx.doi.org/10.1016/ S0166-4328(96)02259-0

Hayasaka, S., \& Nichols, T. E. (2004). Combining voxel intensity and cluster extent with permutation test framework. NeuroImage, 23, 54-63. http://dx.doi.org/10.1016/j.neuroimage.2004.04.035

Kircher, T. T., Senior, C., Phillips, M. L., Benson, P. J., Bullmore, E. T., Brammer, M., ... David, A. S. (2000). Towards a functional neuroanatomy of self processing: Effects of faces and words. Cognitive Brain Research, 10, 133-144. http://dx.doi.org/10.1016/S0926-6410(00) 00036-7

Kühn, S., \& Gallinat, J. (2013). Gray matter correlates of posttraumatic stress disorder: A quantitative meta-analysis. Biological Psychiatry, 73, 70-74. http://dx.doi.org/10.1016/j.biopsych.2012.06.029

Kunzmann, U., Little, T., \& Smith, J. (2002). Perceiving control: A double-edged sword in old age. The Journals of Gerontology, Series B: Psychological Sciences and Social Sciences, 57, P484-P491. http://dx .doi.org/10.1093/geronb/57.6.P484

Lawton, M. P. (1975). The Philadelphia Geriatric Center Morale Scale: A revision. Journal of Gerontology, 30, 85-89. http://dx.doi.org/10.1093/ geronj/30.1.85

Liang, J., \& Bollen, K. A. (1983). The structure of the Philadelphia Geriatric Center Morale Scale: A reinterpretation. Journal of Gerontology, 38, 181-189. http://dx.doi.org/10.1093/geronj/38.2.181

Linden, M., Baumann, K., Lieberei, B., \& Rotter, M. (2009). The PostTraumatic Embitterment Disorder Self-Rating Scale (PTED Scale). Clinical Psychology \& Psychotherapy, 16, 139-147. http://dx.doi.org/ 10.1002/cpp.610

Linden, M., Baumann, K., Rotter, M., \& Schippan, B. (2007). The psychopathology of posttraumatic embitterment disorders. Psychopathology, 40, 159-165. http://dx.doi.org/10.1159/000100005

Linden, M., Baumann, K., Rotter, M., \& Schippan, B. (2008a). Diagnostic criteria and the standardized diagnostic interview for posttraumatic embitterment disorder (PTED). International Journal of Psychiatry in Clinical Practice, 12, 93-96. http://dx.doi.org/10.1080/13651500 701580478

Linden, M., Baumann, K., Rotter, M., \& Schippan, B. (2008b). Posttraumatic embitterment disorder in comparison to other mental disorders. Psychotherapy and Psychosomatics, 77, 50-56. http://dx.doi.org/10 $.1159 / 000110060$

Linden, M., Rotter, M., Baumann, K., \& Lieberei, B. (2006). The posttraumatic embitterment disorder: Definition, evidence, diagnosis, treatment. Boston, MA: Hogrefe.

Linden, M., \& Rutkowski, K. (2013). Hurting memories and intrusions in posttraumatic embitterment disorders (PTED) as compared to posttraumatic stress disorders (PTSD). In M. Linden (Ed.), Hurting memories and beneficial forgetting posttraumatic stress disorders, biographical developments, and social conflicts (Vol. 1, pp. 83-92). London, United Kingdom: Elsevier.

Lupien, S. J., McEwen, B. S., Gunnar, M. R., \& Heim, C. (2009). Effects of stress throughout the lifespan on the brain, behaviour and cognition.
Nature Reviews Neuroscience, 10, 434-445. http://dx.doi.org/10.1038/ $\operatorname{nrn} 2639$

Magariños, A. M., \& McEwen, B. S. (1995). Stress-induced atrophy of apical dendrites of hippocampal CA3c neurons: Comparison of stressors. Neuroscience, 69, 83-88. http://dx.doi.org/10.1016/0306-4522 (95)00256-I

McEwen, B. S. (2013). The Brain on stress: Toward an integrative approach to brain, body, and behavior. Perspectives on Psychological Science, 8, 673-675. http://dx.doi.org/10.1177/1745691613506907

McEwen, B. S., \& Morrison, J. H. (2013). The brain on stress: Vulnerability and plasticity of the prefrontal cortex over the life course. Neuron, 79, 16-29. http://dx.doi.org/10.1016/j.neuron.2013.06.028

McKittrick, C. R., Magariños, A. M., Blanchard, D. C., Blanchard, R. J., McEwen, B. S., \& Sakai, R. R. (2000). Chronic social stress reduces dendritic arbors in CA3 of hippocampus and decreases binding to serotonin transporter sites. Synapse, 36, 85-94. http://dx.doi.org/10 $.1002 /($ SICI) 1098-2396(200005)36:2<85::AID-SYN1>3.0.CO;2-Y

Russell, D., Cutrona, C. E., Rose, J., \& Yurko, K. (1984). Social and emotional loneliness: An examination of Weiss's typology of loneliness. Journal of Personality and Social Psychology, 46, 1313-1321. http://dx .doi.org/10.1037/0022-3514.46.6.1313

Sapolsky, R. M., Krey, L. C., \& McEwen, B. S. (1985). Prolonged glucocorticoid exposure reduces hippocampal neuron number: Implications for aging. The Journal of Neuroscience, 5, 1222-1227.

Schulz, P., Scholtz, W., \& Becker, P. (2004). Trierer Inventar zum chonischen Stress (TICS) [Trier Inventory for Chronic Stress (TICS)]. Göttingen, Germany: Hogrefe.

Soetanto, A., Wilson, R. S., Talbot, K., Un, A., Schneider, J. A., Sobiesk, M., ... Arnold, S. E. (2010). Association of anxiety and depression with microtubule-associated protein 2- and synaptopodin-immunolabeled dendrite and spine densities in hippocampal CA3 of older humans. Archives of General Psychiatry, 67, 448-457. http://dx.doi.org/10.1001/ archgenpsychiatry.2010.48

Sprent, P. (1998). Data driven statistical methods. London, United Kingdom: Chapman and Hall.

Tulving, E. (1983). Elements of episodic memory. New York, NY: Oxford University Press.

Tzourio-Mazoyer, N., Landeau, B., Papathanassiou, D., Crivello, F., Etard, O., Delcroix, N., . . Joliot, M. (2002). Automated anatomical labeling of activations in SPM using a macroscopic anatomical parcellation of the MNI MRI single-subject brain. NeuroImage, 15, 273-289. http://dx.doi .org/10.1006/nimg.2001.0978

Von Der Heide, R. J., Skipper, L. M., Klobusicky, E., \& Olson, I. R. (2013). Dissecting the uncinate fasciculus: Disorders, controversies and a hypothesis. Brain: A Journal of Neurology, 136, 1692-1707. http://dx .doi.org/10.1093/brain/awt094

Vyas, A., Mitra, R., Shankaranarayana Rao, B. S., \& Chattarji, S. (2002). Chronic stress induces contrasting patterns of dendritic remodeling in hippocampal and amygdaloid neurons. Journal of Neuroscience, 22, $6810-6818$

Zeigarnik, B. (1927). Über das Behalten von erledigten und unerledigten Handlungen [On memory of finished and unfinished actions]. Psychologische Forschung, 9, 1-85.

Zysset, S., Huber, O., Ferstl, E., \& von Cramon, D. Y. (2002). The anterior frontomedian cortex and evaluative judgment: An fMRI study. NeuroImage, 15, 983-991. http://dx.doi.org/10.1006/nimg.2001.1008

Received March 14, 2017

Revision received April 29, 2017

Accepted May 5, 2017 